\title{
Mathematical modeling in high tech enterprise innovation and production component enhancing strategy
}

\author{
BATOVA MARINA \\ Department of informatics and management \\ Military University of the Ministry of Defense of the Russian Federation Moscow, 14 \\ Bolshaya Sadovaya st. \\ RUSSIA \\ BARANOVA IRINA \\ Department of Business and Business Administration \\ Russian Presidential Academy of National Economy and Public Administration \\ Moscow, 84 Vernadskiy Prospekt \\ RUSSIA \\ BARANOV VYACHESLAV \\ Department of Business and Business Administration \\ Russian Presidential Academy of National Economy and Public Administration \\ Moscow, 84 Vernadskiy Prospekt \\ RUSSIA
}

\begin{abstract}
For high tech enterprise manufacturing subdivisions production optimization challenge has been defined. Mathematical models have been developed. Implementing model algorithms have been researched. A step-by-step mechanism for algorithm implementation based on Johnson's method is proposed. Developed models have been tested at the enterprises of the innovation-oriented cluster. Model of setting the economically feasible limits of process operations (performed on technological equipment of established manufacturing subdivisions) robotization has been developed.

Key Words: High tech enterprise, mathematical model, discrete programming problem, algorithm of model implementation, Johnson's algorithm, economically feasible limits of robotization, manufacturing robotic subdivision, innovation-oriented cluster.
\end{abstract}

Received: September 28, 2019. Revised: January 30, 2020. Accepted: February 7, 2020. Published: February 20, 2020.

\section{Introduction}

At present, the key factor of Russian enterprises efficient function in turbulent economic environment and successful entering new markets is creation and utilization the system of innovations. In this context, Russian enterprises need to address a number of key challenges aimed at selection of strategy focusing on enhancing the capacity components that provide rapid development. Such challenges are diversification of activities, improvement of flexible manufacturing systems as well as computerization and robotization of business processes. The high tech enterprises focusing on utilization of highly automated equipment served by industrial robots, creation and development of innovation systems have been successful in meeting these challenges. Trend of Russian enterprises transition to the high tech enterprise category is related to the profound modernization of all activities including innovative and manufacturing activities. The basic element of such strategy is innovation sphere, whose development generates fundamental change in other areas. One of the most important challenges for Russian enterprises, in this context, is the innovation system formation [1]. Basic element of this system is technological innovations, which include new products (product innovations) and technology for their production (process innovations). The emergence of these innovations in the enterprises inescapably generates other types of innovations: marketing innovations, management innovations, resource innovations as well as financial innovations and so on. This raises the challenge to consolidate these kinds of innovations into system and manage this system as an integral whole. The emergence of such a system enhances the innovation role in the establishment of a new enterprise development strategy creating 
synergy effect. In this strategy, intangible factors become the basic element of the enterprise fundamental value rising, improving the enterprise competiveness on the high tech products and service global market. Such an approach for enterprise development strategy enables organize production modernization to the best advantage, by linking this modernization to computer-aided process planning (CAPP) and continuous acquisition and life-cycle support (CALS) [7]. Ultimately, it has a positive influence on the country's macroeconomic indicators in a whole.

\section{Problem Formulation}

Production modernization is implemented under upgrading project and implicated the replacement of outdated production capacity to modern ones. This aim is achieved through the establishment of the latest technological processes and manufacturing subdivisions focused on fully automated equipment utilization, application of information systems and so on. Development of the new technologies (process innovations) is closely linked with change in manufactured products, which tends to product innovations emergence in the structure of the enterprise innovation system.

The formation and implementation of production modernization project is preceded by enterprise technological auditing $[2,6]$. The technological audit results allow verifying the technical feasibility of the proposed project solutions as well as establish market advantages, both the products being created (product innovations) and organizational and technological decisions. The scenario planning method utilization allows selecting the best strategy having formed a set of production modernization strategies. In this context, development of strategic decisions may include either improving of existing enterprise development strategy or its complete change through business processes re-engineering. Selection of the best enterprise development strategy is based on economic feasibility and limits criteria, dictated by environmental factors. Based on the findings, new subdivisions manufacturing diversified production are being created. In the context of digital manufacturing such subdivisions should be focused on the robotics utilization. Moreover, the important challenges for these subdivisions are: first, formation of the production program, based on the enterprise order portfolio, second, definition of the economically feasible limits of process operations robotization performed on technological equipment of manufacturing subdivisions.

\section{Problem Solution}

\subsection{Production activities as functional strategy of enterprise innovation performance}

According to the management process approach, the enterprise production activity is one of its functional strategies [3]. The production component appears as the essential feature of high tech enterprise competitive strategy, affecting not only the mechanism of current costs formation, but also the enterprise investment activity final indicators. Quality and competitiveness indicators of product innovations produced by an enterprise are formed, as part of the strategy production component implementation. Ultimately, the parameters characterizing enterprise activity production component participate in the formation of all economic and financial indicators (net proceeds, profit, financial viability, current capacity to pay, turnover and so on). The order portfolio for enterprise products is formed in the process of developing its marketing strategy, with due regard for characteristics of the production capacity [4]. In terms of enterprise competitive strategy effective implementation, the components optimizing challenge raises of this strategy, that is to say functional strategies, including development of the effective production strategy. The solution to this challenge will provide the effective use of technological (process and product) innovations by enterprise and implies establishment of manufacturing subdivisions, as well as day-to-day management technologies. The production processes operational management technology, in turn, requires mechanism for the production optimal program formation from the enterprise order portfolio as well as effective management of enterprise resources. Ultimately, this will provide technological equipment balanced workload as well as rhythmic production output. The solution to this challenge is most relevant for production diversification as flexible response of a high tech enterprise to the market demands provides it with necessary competitive advantages.

\subsection{Development of manufacturing subdivision production program formation mathematical model}

This paper proposes the formation of optimal production program algorithm for a manufacturing subdivision in accordance with the existing specialization, available production capacities as well as order portfolio in general. The following symbols have been introduced in developing production program formation mathematical model: 
$\boldsymbol{g}$ - position number in product range acceptable to inclusion in production plan, $g=1, . ., G$;

$\boldsymbol{G}$ - manufacturing subdivision product range;

$\boldsymbol{Q}_{g}$ - launch plan of $g$-th position number during the production program reproducibility period;

$\boldsymbol{T}_{\boldsymbol{g}}$ - equipment readjustment total time for the manufacture of $g$-th position;

$W$ - effective working hours of equipment, executing the $i$-th operation in manufacturing subdivision production line;

$\alpha_{g}$ - binary variable taking value 1 if an $g$-th product is included in the production program, else 0 .

In the process of developing the mathematical model, the assumption was made about technological equipment cycle in the manufacturing subdivision does not irrespective of position number in the manufactured product range (variable $g$ ) and is equal to the average value $r$. This condition is met, first, the labor intensity range of manufacturing various types of products is not large, second, the production program includes the sufficiently large number of product items. It will be assumed that launches number of the $g$-th product is equal to 1 for the period under review.

In terms of operational-calendar planning, the optimal program formation challenge for the manufacturing subdivision of a high tech enterprise is reduced to finding a column vector whose elements are binary variables $\alpha_{g}$.

First, the found column vector must meet the requirements:

$$
r \cdot \sum_{g=1}^{G} \alpha_{g} Q_{g}+\sum_{g=1}^{G} \alpha_{g} T_{g} \leq \mathrm{W}
$$

Second, must optimize the objective function of the following form:

$$
\sum_{g=1}^{G} \alpha_{g} Q_{g} \rightarrow \max
$$

In terms of mathematical modeling, the formulated problem is a discrete programming issue [5]. For solution to the problem in practice, various heuristic algorithms are applied, which can be fully adapted to form the high tech enterprise subdivision optimal production program.

Most frequently, various algorithms are used to solve this class of discrete programming problems. First, it is an algorithm based on Johnson's method. Second, an algorithm based on the method of increasing time spent on a technological equipment readjustment in manufacturing subdivisions. Third, an algorithm based on the method of decreasing product processing program included in the production plan.

\subsection{Production plan formation algorithm based on Johnson's algorithm}

To do this, a given set of the products range potentially admissible for inclusion in the production plan should be systematized as follows:

In the first step, product for which $Q_{g}$ reaches max value is selected, and $g=1$ is assigned for this product.

In the second step, among the remaining elements of the product set, position of product range is chosen for which $\max T_{g}$ condition is fulfilled and $g=G$ is assigned for this product.

In the third step, among the remaining elements of the set, the product is selected again for which $\max Q_{g}$ is achieved, and $g=2$ is assigned for this product.

Obviously, if this process is continued, the arrangement of the entire product range manufactured in the manufacturing subdivision will be performed in $G$-steps.

Moreover, the production program formation is implemented as follows. Elements of formed sequence are included in the production program, starting from first until the constraints of the formulated model are fulfilled.

\subsection{Selection of input data for the production program formation}

As the input data necessary for calculating the production program are used effective working hours and throughput rate of technological equipment, the processed products range, launches number of the $g$-th product into production during the period under review.

For each item of the products range is set production output program, technological equipment readjustment expended time as well as the effective working hours required to process this type of product item.

The production plan (the actual quantity of produced products) of a high tech enterprise manufacturing subdivision is calculated as follows:

$$
Q_{w_{l}}=Q-Q_{\text {lost }_{l}}-\frac{w_{l}-w_{e f}}{r}
$$

where: $\boldsymbol{I}$ - sequence number of used production program formation algorithm $(l=1,2,3)$;

$\boldsymbol{Q}_{\boldsymbol{w}_{l}}-$ actual produced quantity of products according to the $l$-th algorithm for production plan formation;

$\boldsymbol{Q}_{\text {lost }_{l}}$ - lost production output as a result of exceeding the product processing working hours included in the production plan over the available total equipment working hours;

$W_{l}-$ total time fund for the entire products range included in production plan for $l$-th option of the production plan formation; 
$W_{\text {ef }}$ - manufacturing equipment effective working hours.

Calculations of volume product output produced by manufacturing subdivisions, which used various algorithms, showed that the algorithm based on Johnson's algorithm is the most viable.

The results of solution to the formation optimal production program challenge for a high tech enterprise manufacturing subdivision have been applied in solving a number of particular challenges of operational-calendar planning as well as management of diversified production. In particular, for the Republic of Tatarstan engineering cluster high tech enterprises, the problem of establishing the optimal balance between flexibility and productivity of manufacturing systems utilized by cluster enterprises has been solved.

\subsection{Mathematical modelling of selection economically feasible robotization limits}

The results of the production program formation are the basic condition for solving the problem of determining the economically feasible robotization limits of operations performed in the manufacturing subdivisions. The relevance of solving such a problem is due to the fact that robotization along with informatization is the foundation of the hightech enterprises digital transformation. The combination of informatization and robotization processes into a single project is becoming a key element for a high-tech enterprise to ensure the effectiveness of diversified production [11, 14]. Some relevant studies can be found in $[12,13]$.

The solution to the problem of determining the economically feasible limits of robotization was based on the assumption that each i-th operation is performed on the i-th group of technological equipment. A similar problem was solved under the assumption that the launch of product batch-andqueue within the framework of the formed program is a fixed value. It is assumed that as a result of robotization, the fund of operational time changes. During the development of the model, it was assumed that the fund for the operational time of technological equipment freed up as a result of robotization can be used to produce products that are currently not assigned to this manufacturing subdivision.

The solution of this problem assumes that for each i-th operation of the technological process, the economic feasibility of its robotization is determined. The created model is invariant with respect to the technological operation, the robotization feasibility of which is being established. This is achieved by introducing into the model binary variable $\beta_{\mathbf{i}}$ which takes a value equal to 1 if the $i$-th operation is robotized, else 0 .

A variant of a manufacturing robotic subdivision includes a set of operations whose robotization is economically feasible. Moreover, the robotization of each operation can be carried out using various industrial robots. In the mathematical model, this possibility is taken into account by introducing the index $\mathrm{j}$, which characterizes the type of robot using for robotization purposes.

As the indicator used to assess the feasibility of robotization, the net present value, and the maximum of this indicator as the objective efficiency function has been chosen. The selection of an effective option of a manufacturing robotic subdivision was carried out from a set of options for which a number of conditions are typical. First, the life cycle of the evaluated options is constant, and calculations for these options are performed at current prices, that is prices set excluding inflation. Second, investments in the project of creating robotic units are non-recurring and tied to the beginning of the project. Third, in projects for the developing of manufacturing robotic subdivisions, the maintaining and operating current costs over the intervals of the project life cycle are constant.

Fulfillment of these conditions means that the maximum net present value criteria will be identical to the minimum annual cost criteria of creating and operating manufacturing robotic subdivisions. In this case, in the model for calculating the net present value, the difference between the discounted results and the costs will be the savings obtained by the high tech enterprise from reducing the cost of production produced in manufacturing robotic subdivisions. To develop a model for determining the economically feasible limits of robotization, a number of variables is introduced. As variables characterizing the time parameters of the technological process, the operational time of the ith operation will be considered $\left(t_{i}^{o p}\right)$. This time in turn includes the amount of main time $\left(t_{i}^{m}\right)$, i.e. machining time plus auxiliary time $\left(t_{i}^{a u x}\right)$, time spent on workpiece input.

It is assumed that during robotization, the duration of all components of the auxiliary time, both overlapped and non-overlapped by the main processing time, changes in the same proportion. In addition, the model does not take into account that the loading of some units of technological equipment may be incomplete. Such underloading is possible in the created manufacturing robotic subdivisions. This may be due to the fact that the robotization of the $i$-th operation will lead to a reduction in its execution time and, consequently, an 
increase in productivity. During developing the model, this situation was taken into account. The model stipulates the relationship between a possible increase in productivity and the release of part of the equipment and areas from the production process.

In the mathematical model, the auxiliary time is divided into two components. First, this is the time not overlapped by the main processing time $\left(t_{i}^{\text {ano }}\right)$, and second, the time which is overlapped by the basic processing time $\left(t_{i}^{a o}\right)$. The coefficient taking into account the change in the duration of the i-th operation when using the $j$-th industrial robot in the manufacturing robotic subdivision is indicated in the model by the symbol $\gamma_{\mathrm{ij}}$, and the proportion of auxiliary time in the norm of the operational time of the $\mathrm{i}$-th operation is reflected in the model as $\mathrm{k}_{\mathrm{i}}$

The model introduces variables characterizing technological equipment and robotics. For technological equipment performing the i-th operation, these variables are annual effective time fund $\left(F_{i}^{t e}\right)$, equipment floor space $\left(\mathrm{S}_{\mathrm{i}}{ }^{\text {te }}\right)$, initial purchase price of equipment $\left(\mathrm{P}_{\mathrm{i}}{ }^{\text {te }}\right)$. To develop a model, it is also necessary to have data on annual costs for providing equipment with energy $\left(\mathrm{P}_{i}{ }^{\text {tee }}\right)$ and the ratio between the cost of equipment routine maintenance and its price $\left(\mathrm{b}_{\mathrm{i}}{ }^{\text {te }}\right)$.

For the j-th industrial robot, which is used as supporting facilities for performing the i-th operation, the annual effective time fund $\left(F_{i j}{ }^{i p}\right)$, IR operating room $\left(\mathrm{S}_{\mathrm{ij}}{ }^{\mathrm{ir}}\right)$, initial purchase price, including software costs $\left(\mathrm{P}_{i}^{i}\right)$. By analogy with the equipment, the value of the annual cost of providing the robot with energy $\left(\mathrm{P}_{\mathrm{ij}}^{\mathrm{ire}}\right)$ and the ratio between the cost of robot routine maintenance and its price $\left(b_{i j}{ }^{i j}\right)$ is set.

For the basic option, that is, the option without using robotics, the hourly pay rate (with all charges) of the worker engaged in the $\mathrm{i}$-th operation $\left(\mathrm{C}_{\mathrm{i}}^{\mathrm{hr}}\right)$ is determined. In addition, the cost of developing $\left(\mathrm{C}^{\mathrm{pa}}\right)$, as well as the current maintenance of 1 square meter of production area $\left(\mathrm{P}^{\mathrm{pa}}\right)$ is set.

To calculate the amount of investment costs repayment, the model uses the depreciation rate on the cost of technological equipment $\left(\mathrm{d}^{\mathrm{te}}\right)$, j-th industrial robot $\left(\mathrm{d}_{\mathrm{ij}}{ }^{\mathrm{i}}\right)$ and production space $\left(\mathrm{d}^{\mathrm{pa}}\right)$. To determine the current value of investments in the model, the discount rate (E) is used that is common for all investment objects (technological equipment, robotics and production area), which is defined as weighted average cost of capital (WACC).

Since the economic feasibility of robotization is evaluated not at the level of a high tech enterprise as a whole, but only at the level of its manufacturing subdivisions, the model for calculating the savings in the total cost of creating and operating manufacturing robotic subdivisions is presented in a form that is more convenient for analyzing efficiency factors. The model takes into account the dominant factors that determine the economically feasible limits of robotization, and calculated the change under the influence of these factors, first, the technological cost, and second, investment costs.

The change in technological cost, reflecting the costs of the i-th operation during its robotization, is described in the model by the following components:

a) payroll savings due to the release of workers $\left(\Delta \mathrm{C}_{\mathrm{i}}{ }^{\mathrm{rw}}\right)$ :

$$
\Delta \mathrm{C}_{\mathrm{i}}{ }^{\mathrm{rw}}=\mathrm{Q} \mathrm{C}_{\mathrm{i}}^{\mathrm{hr}} \beta_{\mathrm{i}}\left(\mathrm{t}_{\mathrm{i}}^{\mathrm{ano}}+\mathrm{t}_{\mathrm{i}}^{\mathrm{ao}}\right) / \mathrm{k}_{\mathrm{i}}
$$

b) current costs savings for equipment routine maintenance and energy supply, as well as production area maintenance $\left(\Delta \mathrm{C}_{\mathrm{i}}{ }^{\mathrm{rte}}\right)$ :

$\Delta \mathrm{C}_{\mathrm{i}}^{\mathrm{rte}}=\mathrm{Q}\left[\left(\gamma_{\mathrm{ij}}-1\right) / \gamma_{\mathrm{ij}}\right]\left[\left(1 / F_{i}^{t e}\right) \beta_{\mathrm{i}} \mathrm{t}_{\mathrm{i}}^{\text {ano }}\right]\left(\mathrm{b}_{\mathrm{i}}^{\text {te }} \mathrm{P}_{\mathrm{i}}^{\text {te }}+\right.$ $\left.+\mathrm{P}_{\mathrm{i}}^{\text {tee }}+\mathrm{P}^{\text {pa }} \mathrm{S}_{\mathrm{i}}^{\text {te }}\right)$

c) cost increase due to the introduction of industrial robots in the production system $\left(\Delta \mathrm{C}_{\mathrm{i}}\right.$ iir $)$. This growth is due to an increase in current costs for maintenance and energy supply to the robot, as well as the production area maintenance:

$$
\begin{aligned}
& \quad \Delta \mathrm{C}_{\mathrm{i}}{ }_{\mathrm{iir}}=\mathrm{Q} \beta_{\mathrm{i}}\left(1 / F_{i j}^{i p}\right)\left(1 / \gamma_{\mathrm{ij}}\right)\left(\mathrm{t}_{\mathrm{i}}^{\mathrm{ano}}+\mathrm{t}_{\mathrm{i}}^{\mathrm{ao}}\right)\left(\mathrm{b}_{\mathrm{ij}}{ }^{\mathrm{ir}} \mathrm{P}_{\mathrm{ij}}{ }^{\mathrm{ir}}+\right. \\
& \left.+\mathrm{P}_{\mathrm{i}}^{\mathrm{ire}}+\mathrm{P}^{\mathrm{pa}} \mathrm{S}_{\mathrm{ij}}{ }^{\text {ir }}\right)
\end{aligned}
$$

The change in investment costs during the robotization of the $\mathrm{i}$-th operation in the model is taken into account by calculating:

d) saving investment costs due to the release of equipment and space from the technological process $\left(\Delta K_{i}^{\text {rtes }}\right)$

$$
\Delta \mathrm{K}_{\mathrm{i}}^{\text {rtes }}=\mathrm{Q}\left[\left(\gamma_{\mathrm{ij}}-1\right) / \gamma_{\mathrm{ij}}\right] \beta_{\mathrm{i}}\left(1 / \mathrm{F}_{\mathrm{i}}^{\text {te }}\right) \mathrm{t}_{\mathrm{i}}^{\text {ano }}\left(\mathrm{P}_{\mathrm{i}}^{\text {te }}+\right.
$$
$+\mathrm{C}^{\mathrm{pa}} \mathrm{S}_{\mathrm{i}}^{\text {te }}$ )

e) increase in investment costs due to robotization by the $j$-th industrial robot of the $i$-th operation $\left(\Delta \mathrm{K}_{\mathrm{ij}}{ }^{\mathrm{iir}}\right)$ :

$$
\Delta \mathrm{K}_{\mathrm{ij}}^{\mathrm{iir}}=\mathrm{Q}\left(1 / \gamma_{\mathrm{ij}}\right) \beta_{\mathrm{i}}\left(1 / \mathrm{F}_{\mathrm{ij}}^{\mathrm{ip}}\right)\left(\mathrm{t}_{\mathrm{i}}^{\mathrm{ano}}+\mathrm{t}_{\mathrm{i}}^{\mathrm{ao}}\right)\left(\mathrm{P}_{\mathrm{ij}}^{\mathrm{ir}}+\right.
$$
$\left.+\mathrm{C}^{\mathrm{pa}} \mathrm{S}_{\mathrm{ij}}^{\mathrm{ir}}\right)$

Then, in the model for determining the economically feasible limits of the technological process robotization, the cost savings obtained in the $\mathrm{t}$-th year $\left(\mathrm{C}_{\mathrm{t}}^{\mathrm{s}}\right)$ will be equal to:

$$
\begin{aligned}
& \mathrm{C}_{\mathrm{t}}^{\mathrm{s}}=\mathrm{Q} \sum_{i=1}^{l} \beta_{\mathrm{i}}\left\{\mathrm{C}_{\mathrm{i}}^{\mathrm{hr}}\left(\mathrm{t}_{\mathrm{i}}{ }^{\mathrm{ano}}+\mathrm{t}_{\mathrm{i}}{ }^{\mathrm{ao}}\right) 1 / \mathrm{k}_{\mathrm{i}}+\right. \\
& +\left[\left(\gamma_{i j}-1\right) / \gamma_{i j}\right]\left(1 / \mathrm{F}_{\mathrm{i}}^{\text {te }}\right) \mathrm{t}_{\mathrm{i}}^{\text {ano }}\left[\mathrm{b}_{\mathrm{i}}^{\text {te }} \mathrm{P}_{\mathrm{i}}^{\text {te }}+\mathrm{P}_{\mathrm{i}}^{\text {tee }}+\mathrm{P}^{\mathrm{pa}} \mathrm{S}_{\mathrm{i}}^{\text {te }}+\right. \\
& \left.+\left(d^{\text {te }}+E\right) P_{i}^{\text {te }}+\left(d^{\text {pa }}+E\right) C^{\text {pa }} \mathrm{S}_{i}^{\text {te }}\right]- \\
& -\left(1 / \mathrm{F}_{\mathrm{ij}}{ }^{\mathrm{ip}}\right)\left(1 / \gamma_{\mathrm{ij}}\right)\left(\mathrm{t}_{\mathrm{i}}^{\mathrm{ano}}+\mathrm{t}_{\mathrm{i}}^{\mathrm{ao}}\right)\left[\mathrm{b}_{\mathrm{ij}} \mathrm{ir}_{\mathrm{ij}}^{\mathrm{ir}}+\mathrm{P}_{\mathrm{ij}}{ }^{\mathrm{ire}}+\mathrm{P}^{\mathrm{pa}}\right. \\
& \left.\left.\mathrm{S}_{\mathrm{ij}}{ }^{\mathrm{ir}}+\left(\mathrm{d}_{\mathrm{ij}}{ }^{\mathrm{ir}}+\mathrm{E}\right) \mathrm{P}_{\mathrm{ij}}{ }^{\mathrm{ir}}+\left(\mathrm{d}^{\mathrm{pa}}+\mathrm{E}\right) \mathrm{C}^{\mathrm{pa}} \mathrm{S}_{\mathrm{ij}}{ }^{\mathrm{ir}}\right]\right\}
\end{aligned}
$$

The integral costs per operation hour of the technological equipment performing the i-th operation $\left(Z_{i}^{\text {te }}\right)$ and the $j$-th industrial robot serving the $\mathrm{i}$-th operation $\left(Z_{\mathrm{ij}}{ }^{\mathrm{in}}\right)$ will be: 


$$
\begin{aligned}
& \mathrm{Z}_{\mathrm{i}}^{\text {te }}=\left(1 / \mathrm{F}_{\mathrm{i}}^{\text {te }}\right)\left[\mathrm{b}_{\mathrm{i}}^{\text {te }} \mathrm{P}_{\mathrm{i}}^{\text {te }}+\mathrm{P}_{\mathrm{i}}^{\text {tee }}+\mathrm{P}^{\mathrm{pa}} \mathrm{S}_{\mathrm{i}}^{\text {te }}+\left(\mathrm{d}^{\text {te }}+\mathrm{E}\right) \mathrm{P}_{\mathrm{i}}^{\text {te }}+\right. \\
& \left.+\left(\mathrm{d}^{\mathrm{pa}}+\mathrm{E}\right) \mathrm{C}^{\mathrm{pa}} \mathrm{S}_{\mathrm{i}}^{\mathrm{te}}\right] \\
& Z_{i j}{ }_{i j}=\left(1 / F_{i j}{ }_{i j}^{i p}\right)\left[b_{i j}{ }_{i j} P_{i j}{ }_{i j}^{i r}+P_{i j}{ }_{i j}+P^{p a} S_{i j}{ }_{i j}+\right. \\
& \left.+\left(d_{i j}{ }^{i r}+E\right) P_{i j}{ }^{i r}+\left(d^{p a}+E\right) C^{p a} S_{i j}{ }^{i r}\right]
\end{aligned}
$$

The model for determining the amount of integral costs savings in the $t$-th year of the manufacturing robotic subdivisions creation and operation life cycle will have the following form:

$$
\begin{gathered}
\mathrm{C}_{\mathrm{t}}^{\mathrm{s}}=\mathrm{Q} \sum_{\mathrm{i}=1}^{1} \beta_{\mathrm{i}}\left\{\left[\mathrm{C}_{\mathrm{i}}^{\mathrm{hr}}\left(\mathrm{t}_{\mathrm{i}}^{\mathrm{ano}}+\mathrm{t}_{\mathrm{i}}^{\mathrm{ao}}\right) / \mathrm{k}_{\mathrm{i}}\right]+\right. \\
+\left[\left(\gamma_{\mathrm{ij}}-1\right) / \gamma_{\mathrm{ij}}\right] \mathrm{t}_{\mathrm{i}}^{\mathrm{ano}} \mathrm{Z}_{\mathrm{i}}^{\mathrm{te}}- \\
\left.\left.-\left(1 / \gamma_{\mathrm{ij}}\right)\left(\mathrm{t}_{\mathrm{i}}^{\mathrm{ano}}+\mathrm{t}_{\mathrm{i}}^{\mathrm{ao}}\right) \mathrm{Z}_{\mathrm{ij}}^{\mathrm{ij}}\right]\right\}
\end{gathered}
$$

The resulting formula can be used to solve a range of problems that arise during the development and implementation of projects in the field of production robotization. For example, to solve the problem of determining the economically feasible robotization limits. From a mathematical perspective, this means that in the obtained model, it is necessary to determine the values of the independent variables $\beta_{\mathrm{i}}$ in such a way as to ensure the maximum of the following objective function:

$$
\begin{aligned}
& \sum_{i=1}^{l} \beta_{\mathrm{i}}\left\{\left[\left(\mathrm{C}_{\mathrm{i}}^{\mathrm{hr}} / \mathrm{k}_{\mathrm{i}}-\mathrm{Z}_{\mathrm{ij}}^{\mathrm{ir}} / \gamma_{\mathrm{ij}}\right)\right]\left(\mathrm{t}_{\mathrm{i}}^{\mathrm{ano}}+\mathrm{t}_{\mathrm{i}}^{\mathrm{ao}}\right)+\right. \\
& \left.\left.+\left[\left(\gamma_{\mathrm{ij}}-1\right) / \gamma_{\mathrm{ij}}\right) \mathrm{Z}_{\mathrm{i}}^{\mathrm{te}} \mathrm{t}_{\mathrm{i}}^{\mathrm{ano}}\right]\right\} \rightarrow \max
\end{aligned}
$$

Obviously, the maxima of this function is achieved if $\beta_{\mathrm{i}}=1$ for those operations the expression in square brackets of which is a positive value. Moreover, zero values do not reduce the integral costs of a high tech enterprise for the creation and operation of manufacturing robotic subdivisions. Therefore, it may be considered that $\beta_{\mathrm{i}}$ $=1$, if the following expression takes a positive value:

$$
\begin{aligned}
& {\left[\left(\mathrm{C}_{\mathrm{i}}^{\mathrm{hr}} / \mathrm{k}_{\mathrm{i}}-\mathrm{Z}_{\mathrm{ij}}^{\mathrm{ir}} / \gamma_{\mathrm{ij}}\right)\right]\left(\mathrm{t}_{\mathrm{i}}^{\mathrm{ano}}+\mathrm{t}_{\mathrm{i}}^{\mathrm{ao}}\right)+} \\
& +\left[\left(\gamma_{\mathrm{ij}}-1\right) / \gamma_{\mathrm{ij}}\right) \mathrm{Z}_{\mathrm{i}}^{\mathrm{te}} \mathrm{t}_{\mathrm{i}}^{\text {ano }}>0 \\
& \quad\left[\left(\gamma_{\mathrm{ij}}-1\right) / \gamma_{\mathrm{ij}}\right] \mathrm{Z}_{\mathrm{i}}^{\mathrm{te}}\left[\mathrm{t}_{\mathrm{i}}^{\text {ano }} /\left(\mathrm{t}_{\mathrm{i}}^{\text {ano }}+\mathrm{t}_{\mathrm{i}}^{\mathrm{ao}}\right)\right]+ \\
& +\left(\mathrm{C}_{\mathrm{i}}^{\mathrm{hr}} / \mathrm{k}_{\mathrm{i}}-\left(1 / \gamma_{\mathrm{ij}}\right) \mathrm{Z}_{\mathrm{ij}}^{\mathrm{ir}}>0\right. \\
& \text { Which implies } \\
& \quad\left[\mathrm{t}_{\mathrm{i}}^{\text {ano }} /\left(\mathrm{t}_{\mathrm{i}}^{\text {ano }}+\mathrm{t}_{\mathrm{i}}^{\mathrm{aoo}}\right)\right]>\left(\mathrm{Z}_{\mathrm{ij}}^{\mathrm{ir}} /\left(\gamma_{\mathrm{ij}}-1\right)-\right. \\
& -\left[\left(\gamma_{\mathrm{ij}} \mathrm{C}_{\mathrm{i}}^{\mathrm{hr}} / \mathrm{k}_{\mathrm{i}}\right) /\left(\gamma_{\mathrm{ij}}-1\right)\right]\left(1 / \mathrm{Z}_{\mathrm{i}}^{\mathrm{te}}\right)
\end{aligned}
$$

The expression $t_{i}^{\text {ano }} /\left(t_{i}^{\text {ano }}+t_{i}^{\text {ao }}\right)$ reflects the share of auxiliary non-overlapping $\left(\mathrm{t}_{\mathrm{i}}{ }^{\text {ano }}\right)$ time in the total norm of auxiliary time $\left(\mathrm{t}_{i}^{\mathrm{ano}}+\mathrm{t}_{\mathrm{i}}^{\mathrm{ao}}\right)$. The first term in the right-hand side of the inequality characterizes the ratio of costs associated with the operation of the robot and costs associated with the operation of technological equipment. The second term of the right-hand side is the ratio of the worker wage (taking into account the change in the duration of the operation in the robotic version) and the costs associated with the operation of technological Thus, the robotization of the operation is economically feasible if the relative saving of auxiliary nonoverlapping time exceeds the difference in the relative labor saving of the robot and the worker.

Given result can be used to solve the economic problems of robotics, not only for machining, but also when performing transport, storage and other types of work.

\section{Conclusion}

This paper considers the challenges of mathematical modeling conducted within high tech enterprise innovation and production component enhancing strategy formation. One of these challenges is manufacturing subdivision production program selection from the enterprise order portfolio. This challenge has been solved under assumption that the enterprise order portfolio exceeds the production capacity. Mathematic apparatus based on Johnson's method has been developed. As selecting program parameters such characteristics as an order volume and equipment readjustment time have been utilized. The algorithm proposed in the paper was implemented at the Republic of Tatarstan engineering cluster high tech enterprises and demonstrated high efficiency, which is confirmed by the documents on the model application.

There is no doubt that in order to extrapolate the developed model and make extensive utilization of the results obtained at Russian enterprises, it is necessary to take into account the characteristics of each enterprise. This is achieved by the analysis and processing of statistical information on enterprises activities, statistical data verification and models using various statistical criteria. This might, for instance, require utilization the classical statistical methods. First, the Pearson chi-squared test for verification the data distribution hypothesis, and second, the Student's $t$-test for verification the statistical significance of the obtained model coefficients, or verification the hypothesis of the equality or difference between two average values of two independent samples. These criteria are widely distributed in statistical and econometric studies. The main source of statistics is enterprise formal reporting. (financial and accounting statements, statistical reporting and so on), as well as data obtained by continuous permit monitoring or random monitoring. In the practice of European enterprises, various reports are used, the analysis of which reveals information about the environment, including data on the industrial enterprise activities. The results of such studies can be found in the scientific papers [8] and [9]. 
Such an approach is supposed to be implemented in Russia, and at the national level. A similar initiative, for instance, is embedded in the Ministry of Economic Development of the Russian Federation strategy for the period 2019-2024. According to this strategy, in 2019 the Ministry submitted to the Government of Russia a draft law "On Public Non-Financial Reporting". Currently, the law is undergoing legal examination at the Ministry of Justice of Russia.

The law stipulates that Russian enterprises will provide information not only on financial and economic indicators, but also on "social responsibility" and environmental aspects of activities, such as public non-financial reporting [10]. This reporting is a combination of information and indicators reflecting the strategy, goals, management approaches, as well as the results of the enterprise in the field of social responsibility and sustainable development. It is assumed that the Government of Russia will approve the list of key indicators reflected in public non-financial reporting.

Public non-financial reporting will be required to provide state-owned corporations and companies, including state-owned unitary enterprises with more than 5-billion-ruble income, as well as organizations whose securities are admitted for trading on stock markets. Other organizations will generate public non-financial reporting on an optional basis.

Another problem, the solution of which is reflected in this paper, is setting of economically feasible limits of process operations (performed on technological equipment of established manufacturing subdivisions) robotization. The results of solving this problem allow high tech enterprise not only to select cost-effective robotization strategy but also generate the emergence of management innovations.

This statement is based on the fact that robotization dramatically revamp the methodology for establishing high tech enterprise manufacturing subdivisions, creating a need for the new toolkit utilization for the managing these subdivisions. For example, this raises the challenge of equipment partition into the robotic production units during the developing the organizational structures. This problem must be dealt with in a manner that one robot could service maximum amount of equipment provided that equipment workload will not be lower than planned. Methodology of creation robotic production units will be a form of organizational innovations for the high tech enterprise. Utilization of methodologies such as JIT manufacturing, lean production and more others for created robotic production units and manufacturing subdivisions is reasonable to consider as the management innovations of high tech enterprise. Interaction between these two types of innovations and group of technological innovations is a significant instrument for the high tech enterprise fundamental value growth.

\section{References:}

[1] Andreychikov A.V, Andreychikova O.N. Systems analysis and syntesis of strategic decions in theory of innovations. Mathematical, heuristic and intellectual methods of system analysis and synthesis of innovations. M: Lenand, 2015. - 306 p.

[2] Ryazanova V.A., Liushina E.Yu. Organization and production planning : tutorial for the students of higher education instituions / edited by M.F. Balakina. M. Publishing center «Academia», 2010. - $272 \mathrm{p}$.

[3] Radievskiy M.V. Organization of production: Innovative Strategy for Sustainable Enterprise Development. M.: Infra-M, 2013. - 377 p.

[4] Slack N, Chambers S, Johnston P. Operations Management. M.: Infra-M, 2013. - 790 p.

[5] Struchenkov V.I. Discrete optimization. Models, methods, algorithms for solving applications. M.: Solon-Press, 2016. - 314 p.

[6] Fatfutdinov R.A. Organization of production. M.: Infra-M, 2015. - 544 p.

[7] Shishmaryov V.Yu. Organization and planning of automated production. M.: Academia, 2015. $-304 \mathrm{p}$.

[8] Pierluigi Santosuosso Code of Ethics versus Annual Report: Analysis of Environmental Disclosures, WSEAS Transactions on Business and Economics, Vol. 16, 2019, p.p. 239-250.

[9] Pablo Solórzano-Taborga, Ana Belén AlonsoConde, Javier Rojo-Suárez, Efficiency and Stochastic Dominance in the European Equity Mutual Fund Market, WSEAS Transactions on Business and Economics, Vol. 16, 2019, p.p. 226-238.

[10] RBK official website. - URL: https://www.rbc.ru/business/25/07/2019/5d38e 77b9a794738816e35c2 (date of access: 20.01. 2020) (in Russian).

[11] Pelevin E.E., Tsudikov M.B. Economic efficiency of robotization various types of production / Juvenis Scientia. - 2017, №6. p.p. $13-17$.

[12] Abderrahman Rhouzali, Benayad Nsiri, Mounia Miyara, Mohamed Abid, Method of Modeling of the Control Systems Adapted to the Skills Production Systems, International 
journal of Circuits, Systems and Signal processing, pp.385-390, Volume 13, 2019

[13] Guo-cheng Niu, Zhen $\mathrm{Hu}$, Evaluation and Health Status Prediction Method of Beer Filling Production Line based on Data Mining Technology, International journal of Circuits, Systems and Signal processing, pp. 306-311, Volume 13, 2019

[14] Tolkachev S.A., Kulakov A.D Robotization as a form of neo-industrialization (example of the USA) // The world of new economy. 2016. №2. - p.p. $79-87$. 